\title{
Thoughts on Research on Establishment of Cultural Public Space in Urban Communities
}

\author{
Dongming $\mathrm{He}$ \\ Hubei Institute of Fine Arts, Wuhan Hubei, 30205, China
}

Keywords: Urban community, Cultural public space, Establishment, Thought

\begin{abstract}
Cultural public space in urban communities is a major site for community management and cultural construction. The implementation of community cultural activities and the establishment of various social relations depend on cultural public space in urban communities. Public space in urban communities is the minimum unit for realizing functions of public space as well as a public unit with the longest time of daily contact with people. Full use of public space in urban communities for cultural construction can not only enrich the amateur life of people, but also improve the cultural atmosphere of city. However, there are still some deficiencies in the establishment of cultural public space in urban communities. This paper will analyze problems existing in the establishment of cultural public space in urban communities and then put forward corresponding countermeasures.
\end{abstract}

\section{Introduction}

Formal research on public space in Chinese cities hasn't lasted for long. In particular, the establishment of cultural public space in communities is an emerging concept in recent years. It can be seen through the attention to and the establishment of public space in cities that Chinese society is changing deeply. With Chinese economic development, subsistence problem of people has been solved. People have higher pursuits in life and thought while gradually stepping into well-off society. To meet life demands of people such as leisure and social contact, importance is gradually attached to public space in communities as an important public activity area. Resources of grass-root society have been integrated effectively and social stability has been promoted through the establishment of public space in communities.

\section{Descriptions for cultural public space in urban communities}

Cultural public space in urban communities is an important site in the public area of communities, a cultural presentation of urban space expression and cultural establishment for the residential environment of people. Cultural public space in urban communities can be divided into material cultural public space and intangible cultural public space. Material cultural public space refers to public places or landscape provided for exchange of ideas and entertainment of people. Intangible cultural public space refers to some cultural organizational activities with institutional constraint or non-institutional cultural organizational activities implemented in communities. Cultural public space in urban communities is a main site for cultural establishment and community management as well as effective support for the implementation of cultural activities and social communication in communities. Community cultural construction with public space in communities can not only meet the demand of people for spiritual culture, make people have a sense of belonging and identity for communities and train their ownership of community, but also provide cultural support for community development and give full play to community functions.

However, the establishment of cultural public space in urban communities is faced with a new reform under the influence of rapid development of urban construction. First, a lot of strange faces gradually join in community cultural space established by familiar faces, thus making the original system of public space culture faced with changes. Among the reasons, first, the loosening of household registration system causes the increase of mobility of social members. Rural population gradually moves to cities for employment. Most communities involve both urban residents and alien workers, causing conflicts between urban and rural culture in communities. Second, the reform of 
housing system makes original organization-owned housing in cities replaced by commercial housing. Single communities composed of personnel in the same organization have changed into diversified communities composed of different professions and classes. Differences of class and profession make it difficult for residents in the same community to reach a consensus in culture. Then, material cultural public space available in urban communities gradually reduces. The entry of a lot of rural people and the increase of outcomers make urban resident population increase sharply. Due to limited land resources in cities and pursuit of developers for interests, residential housing in cities becomes higher and denser, previous multi-storey and low-density housing gradually reduces and public space area in urban communities is gradually swallowed. With gradual decrease of public space area, the communication and interaction among community residents decrease, thus causing the lack of sense of trust and identity for communities. Traditional community cultural construction also disappears.

According to the analysis above, the establishment of community cultural public space is very important in modern urban construction, which is not only a channel impelling residents to participate in community cultural construction, but also a major site for community cultural communication and integration. It plays a vital role in the promotion of cultural communication among community residents and the completion of cultural integration of residents and provides residents with more leisure space and items under the pressure of high-density living space. It is a main approach for establishing a harmonious living environment and increasing the residence of residents.

\section{Problems faced by cultural public space in urban communities}

\section{Inadequate supply for material cultural construction of cultural public space in urban communities}

Material cultural public space in urban communities is a major site for community residents to implement cultural communication and cultural activities as well as a manifestation of the construction of cultural features. Due to the shortage of urban land and the lack of cultural construction understanding of planning department, the construction of cultural facilities in urban community construction is inadequate and the planning and construction of cultural activity site and cultural landmark buildings cannot meet the demand of residents for cultural communication and study. According to the survey on demand for material cultural public space, about $80 \%$ people expect to increase outdoor activity site in communities, about $50 \%$ people expect to increase indoor activity site and about $50 \%$ people expect to increase sports facilities ${ }^{[2]}$.According to the survey on demand of urban residents for material culture, people have gradually increasing requirements for life quality, especially sites for various indoor and outdoor activities that can bring people pleasure and promote interpersonal communication with the improvement of living standard. Therefore, the demand of community residents for material cultural construction in communities becomes an urgent problem to be solved in community construction. Increasing the construction of site for cultural and sports activities in community public cultural space becomes a necessary measure.

\section{Inadequate use of material public space in establishment of cultural public space in urban communities}

According to the interview on the establishment of community public space, the use of public space is inadequate in many communities, which causes serious waste of space resources. It can be analyzed in two aspects: first, the use of public space in communities is inadequate. According to the survey on area and population of community public space, public space in most communities is much larger than that specified in public service facility planning and design indicators. However, the survey on the use of public space shows that less than $50 \%$ people use public cultural and sports facilities in communities and only about $20 \%$ people use them frequently. About $60 \%$ people have never used them. Some residents have no time for this. Besides, two reasons cause inadequate use of public cultural and sports facilities in cities: first, most residents indicate that cultural and sports facilities are single, most of which are set up for the aged and children. There are few public facilities for young people; second, such facilities cannot be repaired in time after damage. Many facilities are directly discarded after damage. Therefore, there are fewer and fewer cultural and sports facilities. Meanwhile, the lack of resource sharing of cultural public space is a main reason causing inadequate 
use of material public space ${ }^{[3]}$. Resource distribution of public cultural space in communities is unbalanced. Public space resources in different communities have great differences. Some communities have abundant resources, while resources in some communities are lacking. Though uneven resource distribution has great relation with the investment of communities and developers, the lack of openness of community public space seriously influences even distribution of resources. Public resources in many communities are not open to the public, thus resulting in inadequate public space resources in some communities and the waste of public space resources in some communities. In addition, there are many social organizations in some communities, such as schools and units. Such social organizations have adequate public resources, especially in vacation. Their public resources are not utilized, and they are unwilling to share them with community residents. For example, public facilities and sites such as school playground, library and activity auditorium in units are hardly open to the public, thus causing the failure to maximize resource utilization. Therefore, the closure of public space resources in communities and social organizations is one of the reasons causing inadequate utilization of material cultural public space in urban communities.

\section{Lack of characteristics in construction of cultural public space in urban communities}

The lack of characteristics in community cultural public space is a main reason causing the failure of effective utilization of community public resources. According to the analysis on community cultural construction, the lack of characteristics of cultural space can be manifested in two aspects: first, specific resource development of communities is lacking. Each community contains people with different cultural background and professional characteristics. Differences in culture, profession and region make people have different characteristics. Under the action of pluralistic population, each community has characteristic regional cultural features. Meanwhile, diversified population requires diversified cultural construction in urban communities for adaptation. However, most communities have no awareness about these social resources available or the utilization of such resources in the establishment of community cultural public space, thus causing the lack of a characteristic cultural material carrier in the construction of community cultural public space, uniform construction mode of public space in urban communities and the lack of characteristic cultural manifestation and sense of design. With the improvement of living standard, people attach more and more importance to cultural life. However, the shortage of urban land is caused by the enhancement of urban construction and the pursuit of developers for interest. Therefore, even if some communities have the awareness of injecting cultural elements into community construction, few developers can cooperate in community construction and reserve adequate land resources for the construction of community cultural public space as cultural activity site ${ }^{[4]}$.Due to the limit of space and fund, it is difficult for some communities to implement the construction of public cultural space effectively. They can only modify some old houses to be discarded, property management real estate or other houses. Such space is characterized by small space, poor environment and simple equipment. It is difficult for such cultural public sites to attract residents. Second, cultural activities or clubs of social organizations are single and lack innovation. The influence of cultural material space and cultural resources in urban communities causes the lack of characteristics in the construction of community cultural organization. Cultural organizational activities of each community are substantially the same, mainly involving small activities with monotonous contents. In most communities, residents are organized to attend activities such as cards playing, mahjong or film watching. Such activities can hardly meet the pursuit of residents for diversified cultural life. Communities neglect the development of potential resources, thus causing the shortage of originally scarce cultural and recreational resources. The original intention of community cultural construction is to provide community residents with abundant and colorful recreational activities and make residents relax. For example, activities such as chorus, dancing and ball playing can effectively promote interpersonal communication, eliminate fatigue, delight the mind and body, further enrich cultural activities of communities and fully reflect community functions. However, the implementation of cultural activities is too single in actual community cultural construction. Many activities just go through the motions or are carried out for examination. Therefore, functions of the establishment of community culture cannot be manifested. 


\section{Countermeasures for establishment of cultural public space in urban communities}

\section{Improve urban community cultural system and policy}

The government should provide adequate hardware facilities for material cultural space in communities, such as community activity center and gym, and provide certain financial support for community construction. Meanwhile, as infrastructure construction under the jurisdiction of government sectors, urban communities not only require financial and hardware support of the government, but also need certain guarantee of institution and system of the government. The government should issue corresponding management methods to eliminate household registration system and reduce the influence of social class on community residents and social isolation phenomenon formed among different individuals.

\section{Establish open community and social organizations and realize resource sharing}

Openness must be considered in urban community cultural construction. Just as stagnant water in a lake, an isolated system will inevitably deteriorate as time passes by. The establishment of open communities and social organizations can form a virtuous cycle. A steady state can form through the exchange of material and ability ${ }^{[5]}$.The government responsible for community jurisdiction can conduct open management over resources of each community, organize activities among communities and expand the radius of cultural communication in communities. The coordination of internal and external resources can realize maximum realization of resources, enrich amateur life of residents and improve the utilization of cultural resources in urban communities.

\section{Establish characteristic community cultural public space}

Communities can unite with other cultural units to deeply explore internal cultural resources and highlight community features through the exploration and integration of internal resources of communities. For example, some communities are previous school residential buildings. Then, the original culture can be inherited in cultural construction and cultural establishment can be conducted with the theme of "gardener residence". Meanwhile, cultural features of communities can be highlighted with sculpture and publicity board and community logo can be designed with the collection of residents' opinions. In addition, diversified cultural communities can be established according to profession, education and age of residents, thus forming community cultural carrier system with local characteristics.

\section{Conclusion}

In conclusion, the establishment of community cultural public space can not only meet the pursuit of people for spiritual culture, but also provide cultural support for community construction. It has great significance for urban cultural construction. Therefore, the government and communities should fully use public space resources, deeply explore cultural elements and establish a stable, characteristic and diversified community cultural public space.

\section{References}

[1] Gao Chunfeng, Zhao Zhongjie. Thinking on Establishment of Cultural Public Space in Urban Communities. Management Observer, 2012(14):231-234.

[2] Liu Zhongqi. Integration of Public Space Building in Urban Communities and Mobilization of Grass-root Society-Case Analysis Based on G Community in Shanghai. City View, 2012(6):156-167.

[3] Li Tongyue, Zhou Bo, Zhang Biwei et al. "Cell Differentiation”: Analysis on Evolution of Community Public Space-Contrastive Analysis on Street Type Living Area and Modern Residential Quarter. Sichuan Building Science, 2012,38(4):231-234.

[4] Zhu Wen. Study on Improvement Strategies of Public Intercourse Space in High-density Urban Communities. Art Education Study, 2015(13):68-69. 
[5] Zhu Wen. Study on Program for Public Intercourse Space in High-density Urban Communities. Art Science and Technology, 2015(10):41-42. 